\title{
Effects of Out-Of-Class Assignment Frequency on Course Performance in Mechanical Engineering Undergraduates
}

\section{Dr. Kevin Skenes, The Citadel}

Kevin Skenes is an assistant professor at The Citadel. His research interests include non-destructive evaluation, photoelasticity, manufacturing processes, and engineering education.

\section{Dr. Jason Howison, The Citadel}

Jason Howison is an assistant professor of mechanical engineering at The Citadel. His research areas include computational fluid dynamics, wind turbine aeroelasticity, and engineering education.

\section{Dr. Emily Kate Bierman, The Citadel}

Dr. Emily Bierman is an Assistant Professor in the Department of Mechanical Engineering at The Citadel. She received her B.S. in Mechanical Engineering from Purdue University, her M.B.A. from Clarke College, her M.S. in Mechanical Engineering from University of Wisconsin, and her Ph.D. in Mechanical Engineering from North Carolina State University. Her research and interests' areas include high pressure combustion, internal combustion engines, and engineering education. 


\title{
Effects of Out-Of-Class Assignment Frequency on Course Performance in Mechanical Engineering Undergraduates
}

\author{
Kevin Skenes, Jason Howison, and Emily Bierman \\ The Citadel, Charleston, SC
}

\begin{abstract}
Effective out-of-class homework assignments are critical to the success of an engineering curriculum. The number and length of these assignments play a crucial role in their ability to help students comprehend and retain recently acquired knowledge. Assignments that are too infrequent are often put off until right before the due date, at which point the effort put into completion is often rushed and haphazard. Frequent assignments must be of proper difficulty, or students can get frustrated with the large amount of time put into the class with disproportionately small returns. The authors of this paper seek to examine the effects of the frequency of these out-of-class assignments on course performance. The Mechanical Engineering department at The Citadel recently switched multiple junior- and senior-level engineering classes away from approximately weekly homework assignments. Students now receive smaller assignments after every lecture. The authors, who are the instructors of these courses, collected student data from three junior-level courses and one senior-level course over a span of three years. Multiple metrics were used for comparison between the two strategies. These metrics include time spent out of class on the course between lectures, homework performance, performance on in-class embedded indicators, and overall course performance. Furthermore, the student population instructed by the department includes a diverse mix of traditional and non-traditional students, including a number of veterans. These non-traditional students were affected in a manner differing from the traditional student body. This paper describes the comparative results of both homework strategies for both traditional and nontraditional engineering undergraduates.
\end{abstract}

\section{Keywords}

Homework, assessment, embedded indicator, engineering, education

\section{Introduction}

Students of any discipline are familiar with homework, as many receive their first assignment as a 6-year-old and spend a considerable portion of the next 15 years completing many more. The role of homework in education has been source of contention for some time among students $(1,2)$ and teachers (3). Most student learning takes place outside of a classroom setting $(4,5)$, indicating that homework is of great importance to the development of subject comprehension. Numerous studies have been carried out on the relationship between time spent on homework and course performance. These studies look at a range of student ages as well as subjects, and may come to different conclusions. High school Algebra I students who received more homework assignments than their peers were found to perform better on an end-of-course assessment exam (6). This study also noted a statistically significant increase in performance 
when homework is graded for accuracy. At the collegiate level of mathematics, research performed across five universities found that Calculus I students responded well to online homeworks due to the instant feedback provided and the ability to attempt problems multiple times (7). Students in an introductory educational psychology course also performed better on exams when their homework was graded for accuracy and returned with feedback (8). Juniorlevel engineering students reported higher levels of confidence with the material under a homework grading scheme where they are allowed to submit once, receive immediate feedback, correct their initial work, and submit again $(5,9)$.

One of the key questions related to homework involves the time spent by students completing the assignments. An analysis of existing literature by Trautwein (10) notes a correlation between homework and achievement at the class and student levels in $8^{\text {th }}$ and $9^{\text {th }}$ grade students.

However, Trautwein cautions against excessively lengthy homework assignments, noting that the "time on homework" measure does not necessarily correlate with achievement. Similarly, multilevel analysis across 40 countries found that the positive association between homework time and mathematics achievement decreased significantly after controlling for socioeconomic background and school track (11). Furthermore, evidence exists that replacing homework with in-class quizzes has a positive effect on student performance $(12,13)$, although the best approach still seems to be a combination of homework and quizzes.

\section{Current Work}

The authors of this paper seek to examine the frequency of homework assignments on classroom performance. While the "time on homework" variable does not seem to accurately predict achievement, there is some indication that the frequency of assignments does (10). The authors' observation that many engineering students struggle with homework due to poor timemanagement skills is supported by literature (14). All three authors decided independently to address the time management problem by instituting a regular "routine" of scheduled homework that would follow a consistent schedule of assignments and due dates. Three homework strategies have been tried since 2015: homework assigned every week, homework assigned every lecture (referred to as "daily" from this point forth for the sake of brevity), and a system in which students submit the same homework assignment for each class meeting during one week, with feedback occurring after the first submission (5). The time spanned by the collected data also allowed the authors to survey students who had experience all three homework strategies.

\section{Description of Homework and Courses}

Mechanical Engineering undergraduates at The Citadel are required to take MECH 340 (Manufacturing), MECH 310 (Thermofluids I), and MECH 311 (Thermofluids II) as juniors. They are also required to take MECH 415 (Heat Transfer) as seniors. These four courses were originally designed with weekly homework assignments, but the authors have changed the homework structure of each course to smaller assignments after every lecture (hereby referred to as "daily" for the sake of brevity). Each section of these courses was taught by one of the authors. Overall, 33 sections of courses from 2015-2019 were analyzed, resulting in a sample size of $\mathrm{N}=633$ students total. These students were split into 540 traditional students and 93 non-traditional students. "Traditional" in this case refers to students who enrolled in college 
immediately after completing high school, while "non-traditional" refers to students who spent time in other activities between high school and college, often in a career or in the military.

The course summaries for the four courses in question are shown below in Figures 1-4.

\section{MECH 310 Thermal-Fluid Systems I \\ Course Syllabus \\ Fall 2018}

Prerequisites: MATH 132, PHYS 221, PHYS 271

Prerequisites or Corequisites: MATH 231, CIVL 301

\section{Course Description:}

Thermal-Fluid Systems I is an integrated study of fundamental topics in thermodynamics and fluid mechanics. The course introduces conservation principles for mass, energy, and linear momentum as well as the 2 nd Law of Thermodynamics. Principles are applied to incompressible flow in pipes and turbomachinery, external flows, power generation systems, refrigeration cycles, and total air-conditioning focusing on the control volume approach. Laboratory exercises are integrated into classroom work. This course includes completion of a comprehensive, out-of-class design problem. This design problem provides the opportunity for students to apply engineering science and the engineering design process to a hands-on project. Lecture: 2 hours. Laboratory: 2 hours.

Figure 1. MECH 310 Course Description

\section{MECH 311 Thermal-Fluid Systems II \\ Course Syllabus \\ Spring 2019}

\section{Prerequisites or Corequisites: $\mathrm{MECH} 310$}

\section{Course Description:}

Thermal-Fluid Systems II continues the integrated study of fundamental topics in thermodynamics and fluid mechanics. The course applies conservation principles for mass, energy, and linear momentum as well as the 2 nd Law of Thermodynamics. Principles are applied to an automotive system to examine engine performance (Otto and Diesel Cycles) and heat exchangers and to high performance aircraft to examine the Brayton Cycle, compressible flow, external flow, lift, and drag. Laboratory exercises are integrated into classroom work. This course includes completion of a comprehensive, out-of-class design problem. This design problem provides the opportunity for students to apply engineering science to the design of a comprehensive thermal-fluid system. Lecture: 2 hours. Laboratory: 2 hours.

Figure 2. MECH 311 Course Description 


\section{MECH 340 Manufacturing Processes \\ Course Syllabus}

Fall 2019

Prerequisites: CIVL 304/307

Course Description: Common manufacturing processes will be introduced and design guidelines will be developed for each process. The successful student will leave this class with an appreciation that a designer must consider the method of manufacture during the design process to ensure that a product is functional, economically viable, and safe. Basic principles of metal processing; applied mechanics of metal cutting and forming; cost analysis of manufacturing operations.

Figure 3. MECH 340 Course Description

\section{MECH 415 Heat Transfer Course Syllabus \\ Fall 2019}

Prerequisites: MATH 234, MECH 311

\section{Course Description:}

The three modes of heat transfer (conduction, convection, and radiation) are studied in detail, and applications are made to various engineering components including plane walls, finned surfaces, and tube arrays. The principles of conduction and convection are used to study the design and operation of heat exchangers. Numerical methods are employed to study 2D conduction.

Figure 4. MECH 415 Course Description

Importantly, the authors all kept the number of homework problems assigned over the entire semester very nearly the same, regardless of homework frequency. Weekly homework assignments would have three or four problems each, while daily homework assignments would only have one. This results in roughly the same number of total problems worked by the students over the course of a semester regardless of assignment frequency. 


\section{Results}

The most noticeable result involved the number of assignments submitted late or not submitted at all. Weekly assignments were more likely to be submitted late, but daily assignments were more likely to not be submitted. Figure 5 illustrates the difference.

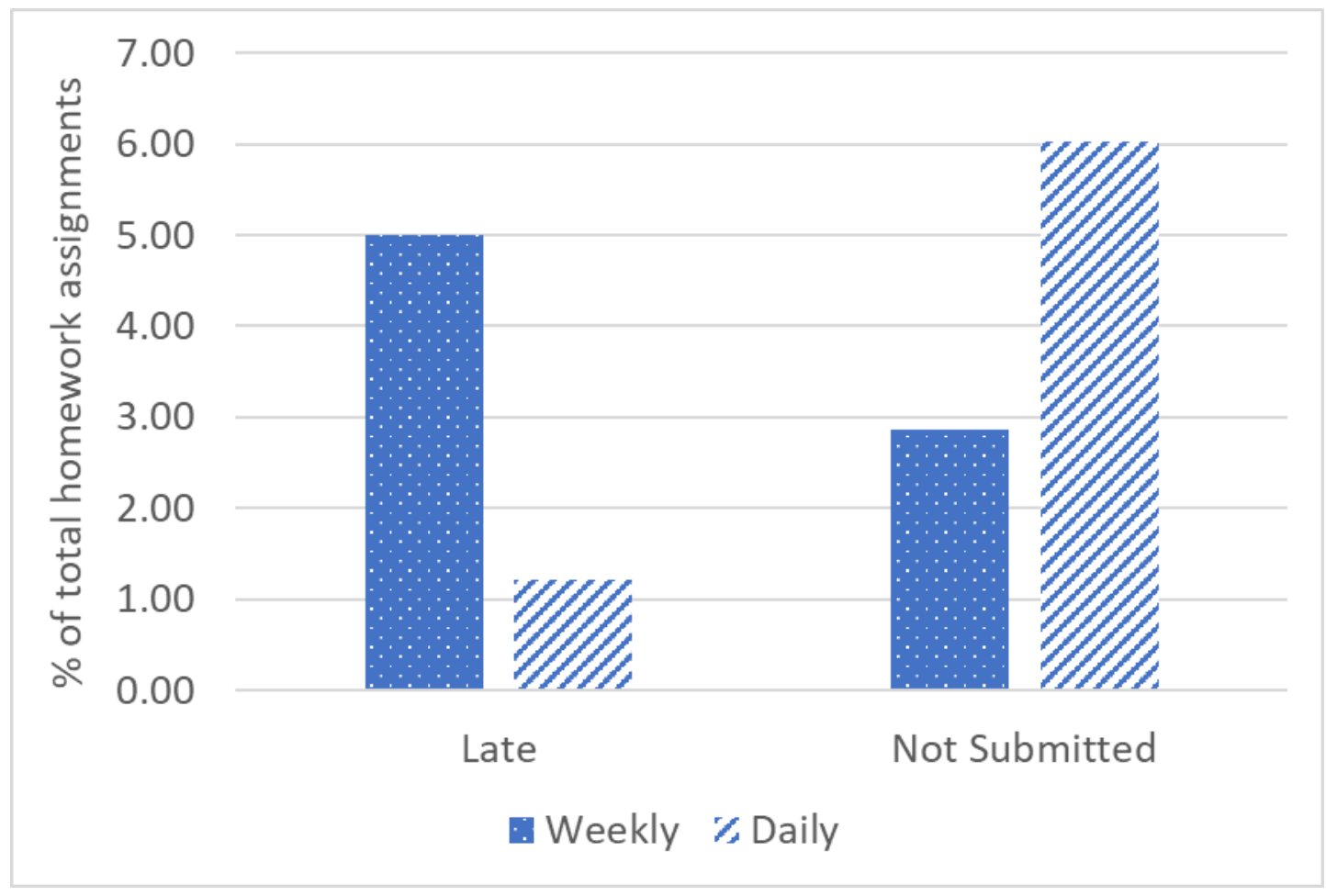

Figure 5. Homework submission data

Students were five times more likely to turn in weekly homework assignments late. However, they were also more than twice as likely to never turn in daily homework assignments. The authors attribute this trend to students feeling that daily homework assignments, which are necessarily smaller and thus worth less points, are more "disposable." Students who do not turn in a 20-point weekly homework assignment on time are more motivated to complete the assignment late and gain some partial credit. Students who do not turn in a 5-point daily homework assignment on time are more likely to consider those points an acceptable loss and move on to the next assignment. This data is correlated by a ranking of all 33 course sections in the data set by homework submission percentage. Four of the five sections with the highest percentage of non-submission assigned homeworks daily, while the five sections with the lowest percentage of non-submission assigned homeworks weekly.

Trends involving homework, exam, and course averages are not as clear. Figures 6-8 illustrate average homework grades for all students, traditional students, and non-traditional students, respectively. Figures 9-11 and 12-14 provide data for average exam grades and average overall course grades. 


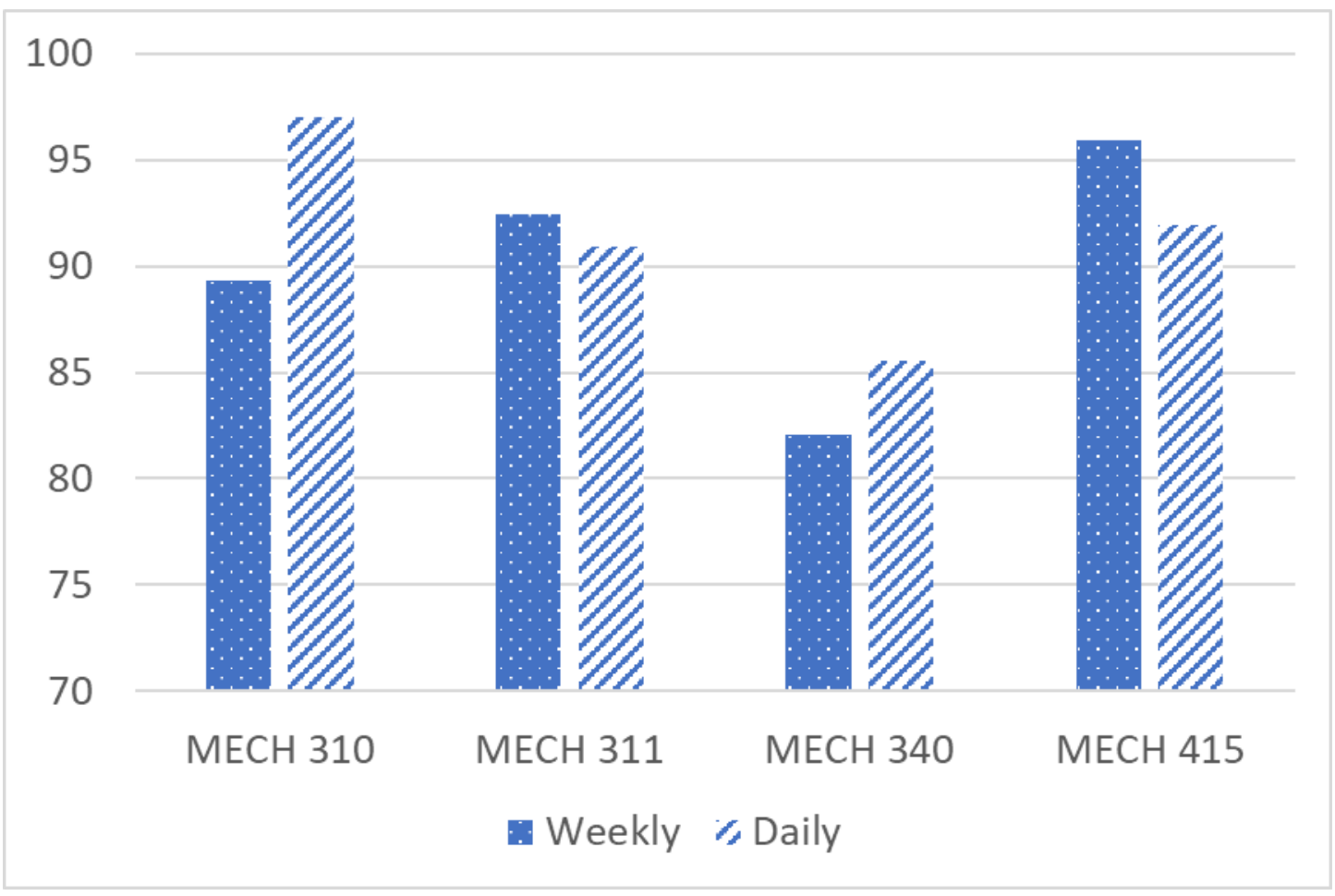

Figure 6. Average homework grade - all students

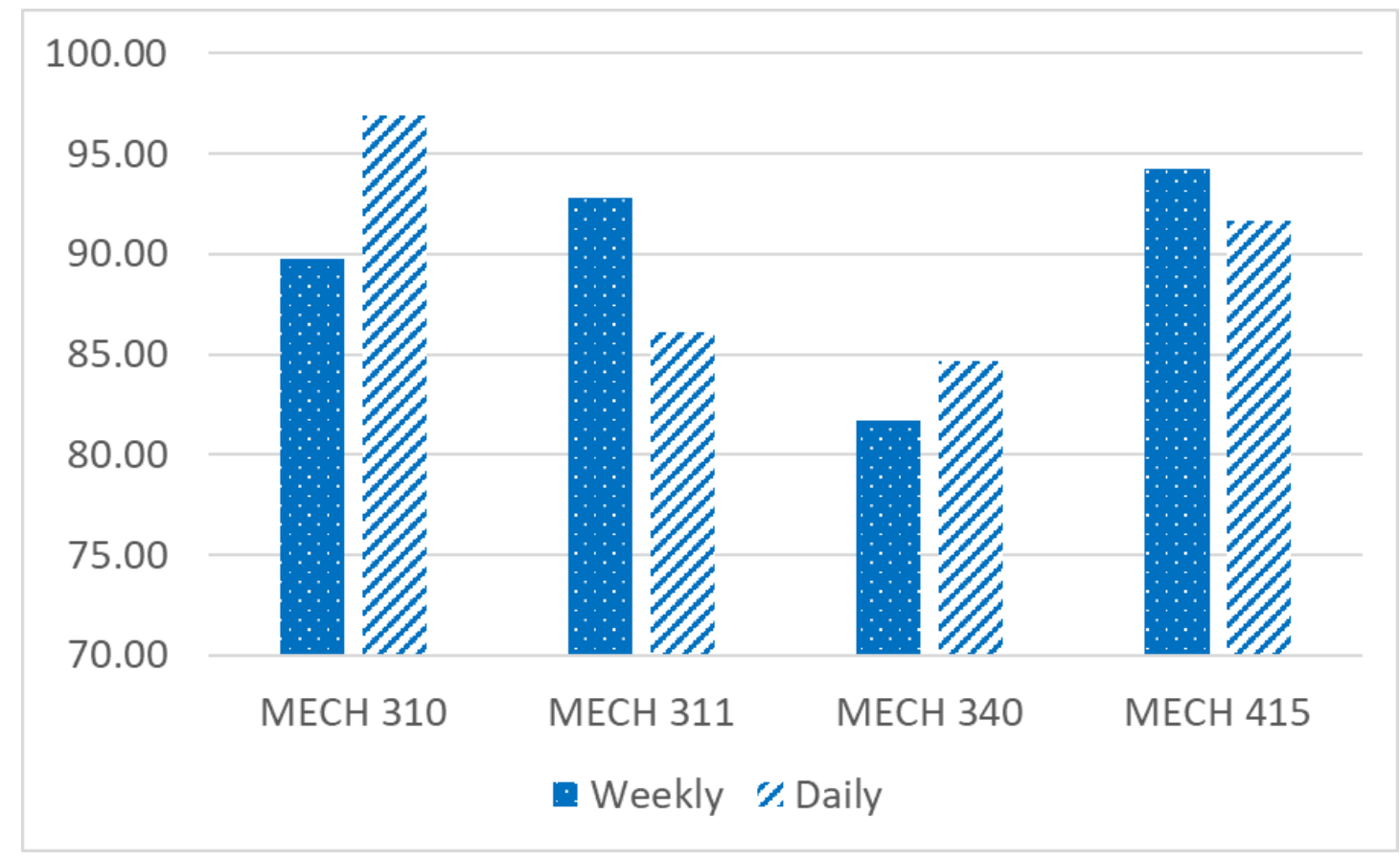

Figure 7. Average homework grade - traditional students 


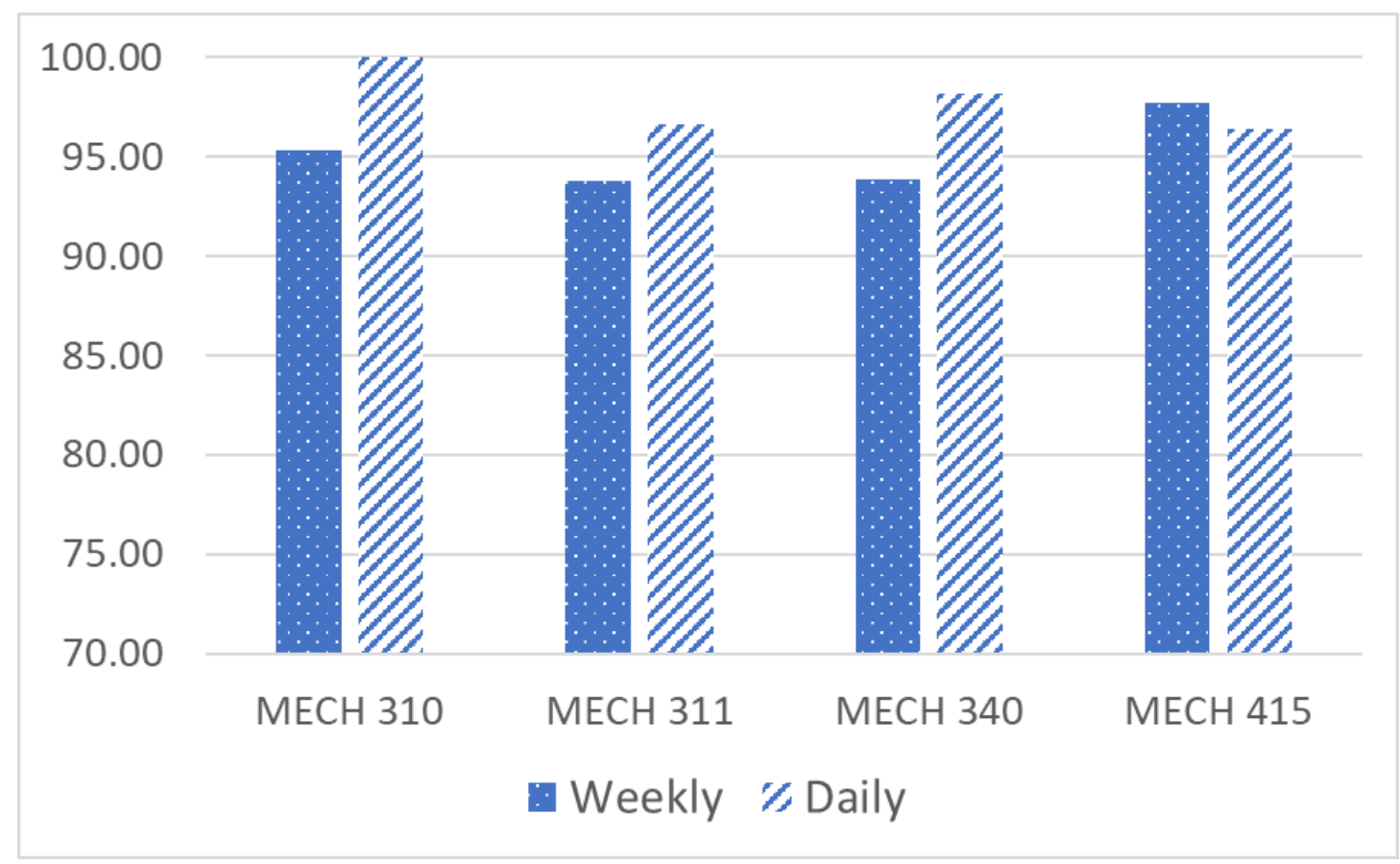

Figure 8. Average homework grade - non-traditional students

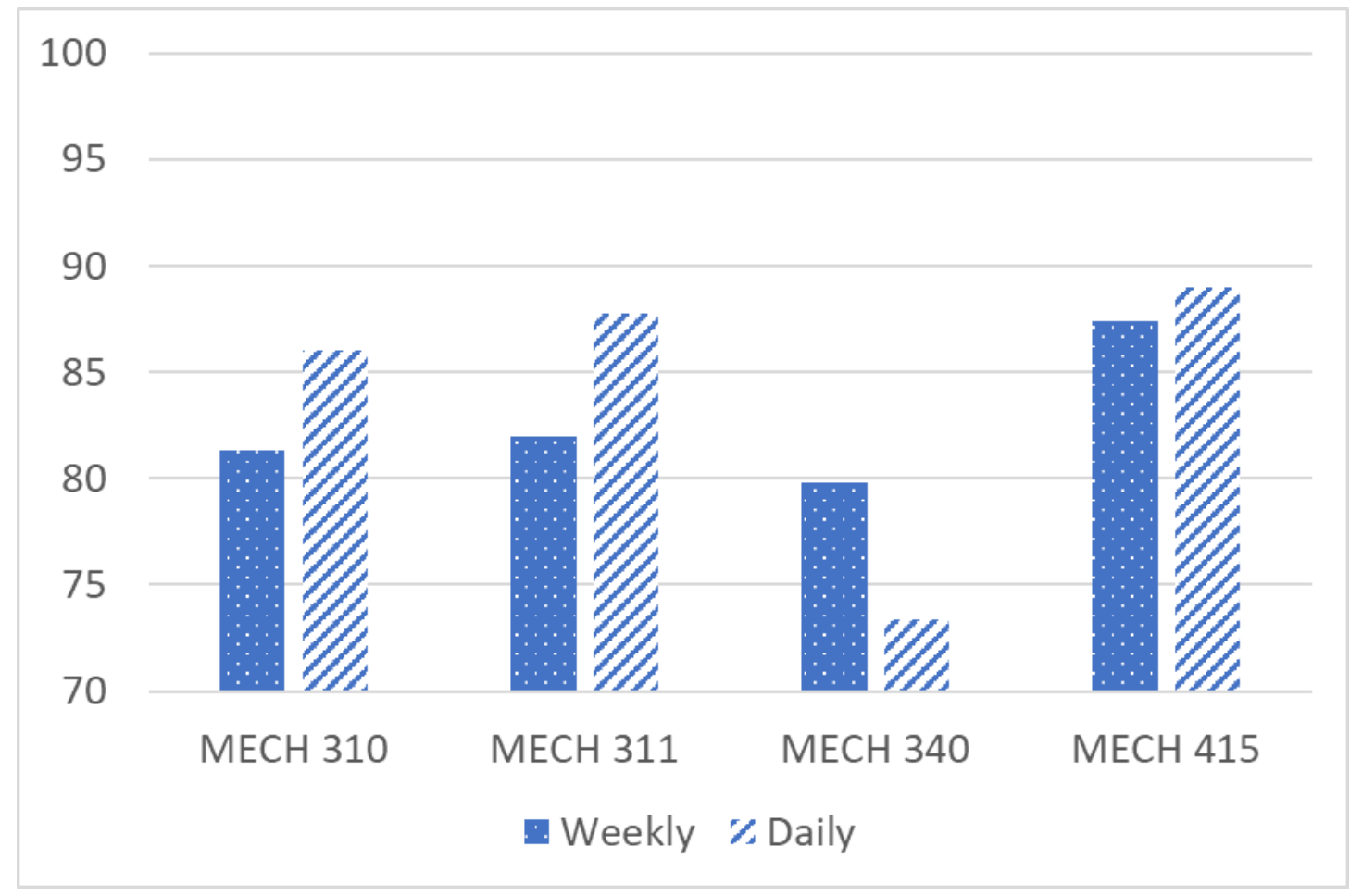

Figure 9. Average test grade - all students 


\subsection{0}

\subsection{0}

90.00

85.00

80.00

75.00

70.00

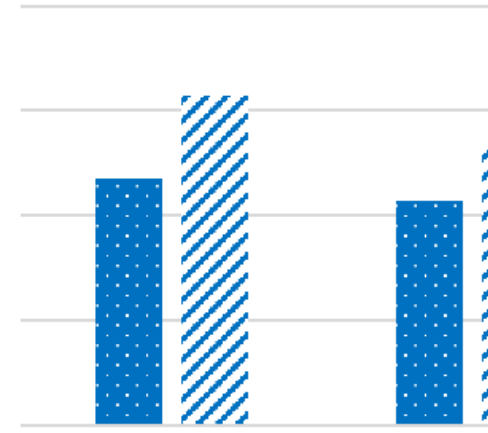

MECH 310

MECH 311

MECH 340

MECH 415

Weekly /2Daily

Figure 10. Average test grade - traditional students

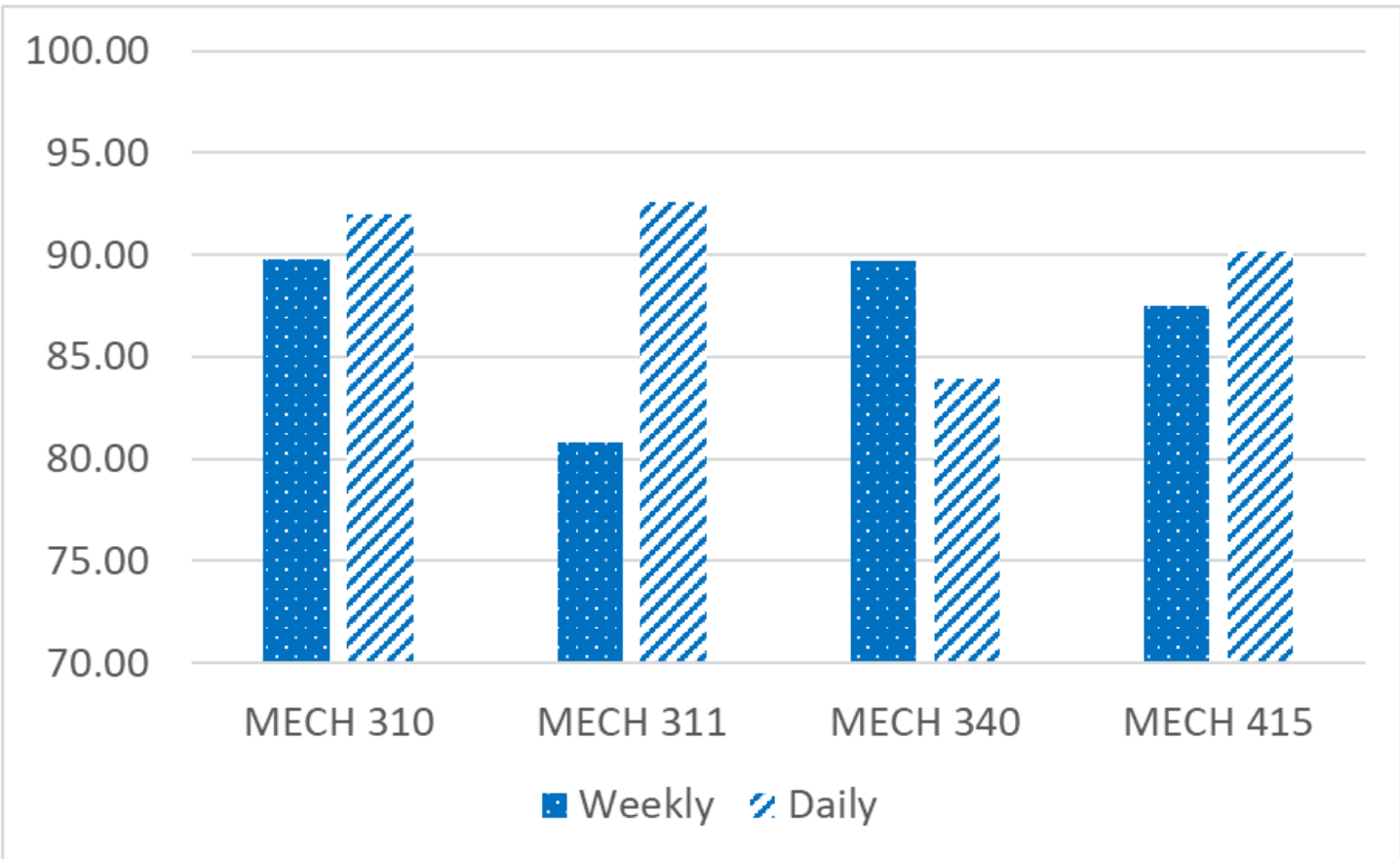

Figure 11. Average test grade - non-traditional students 


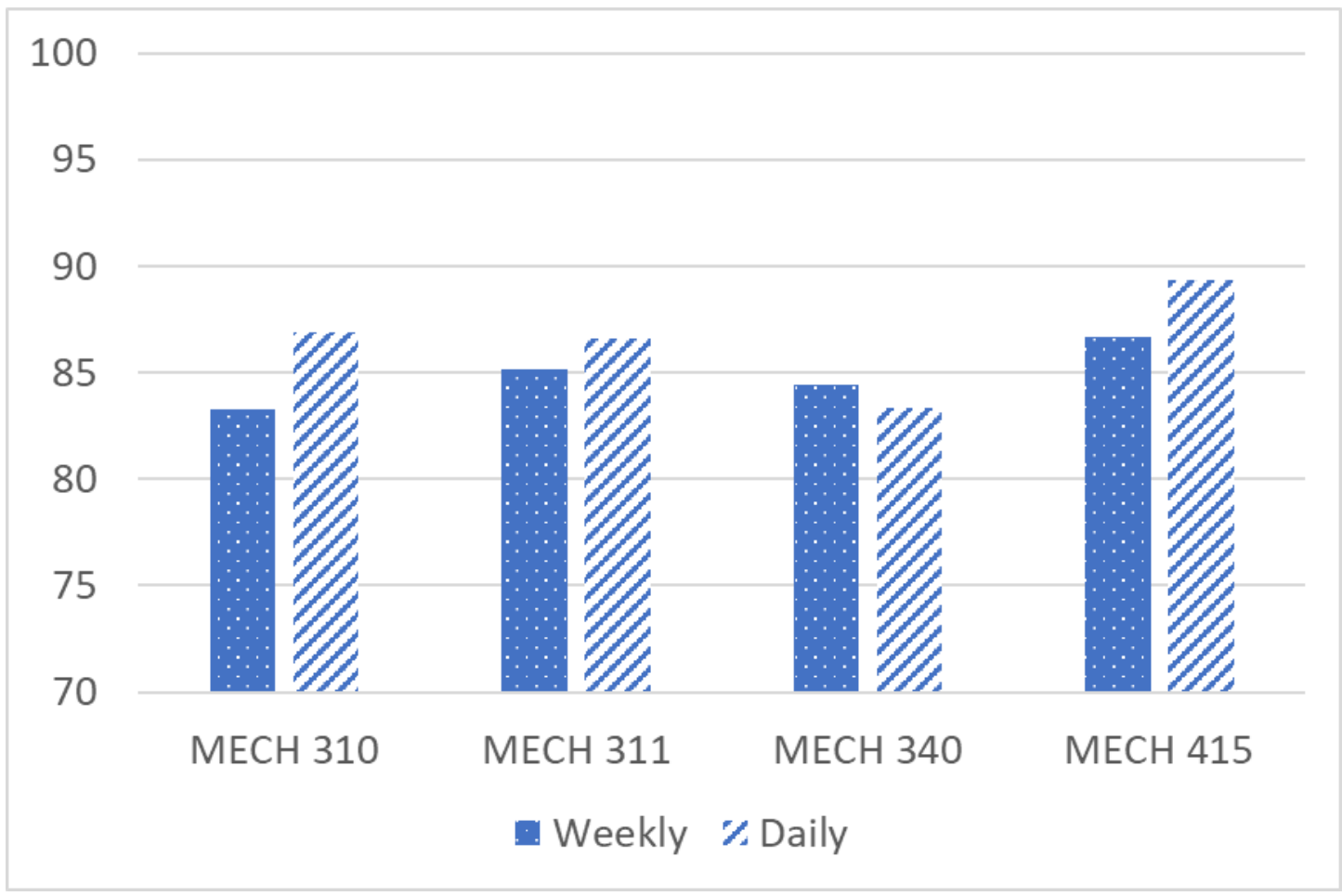

Figure 12. Average overall course grade - all students

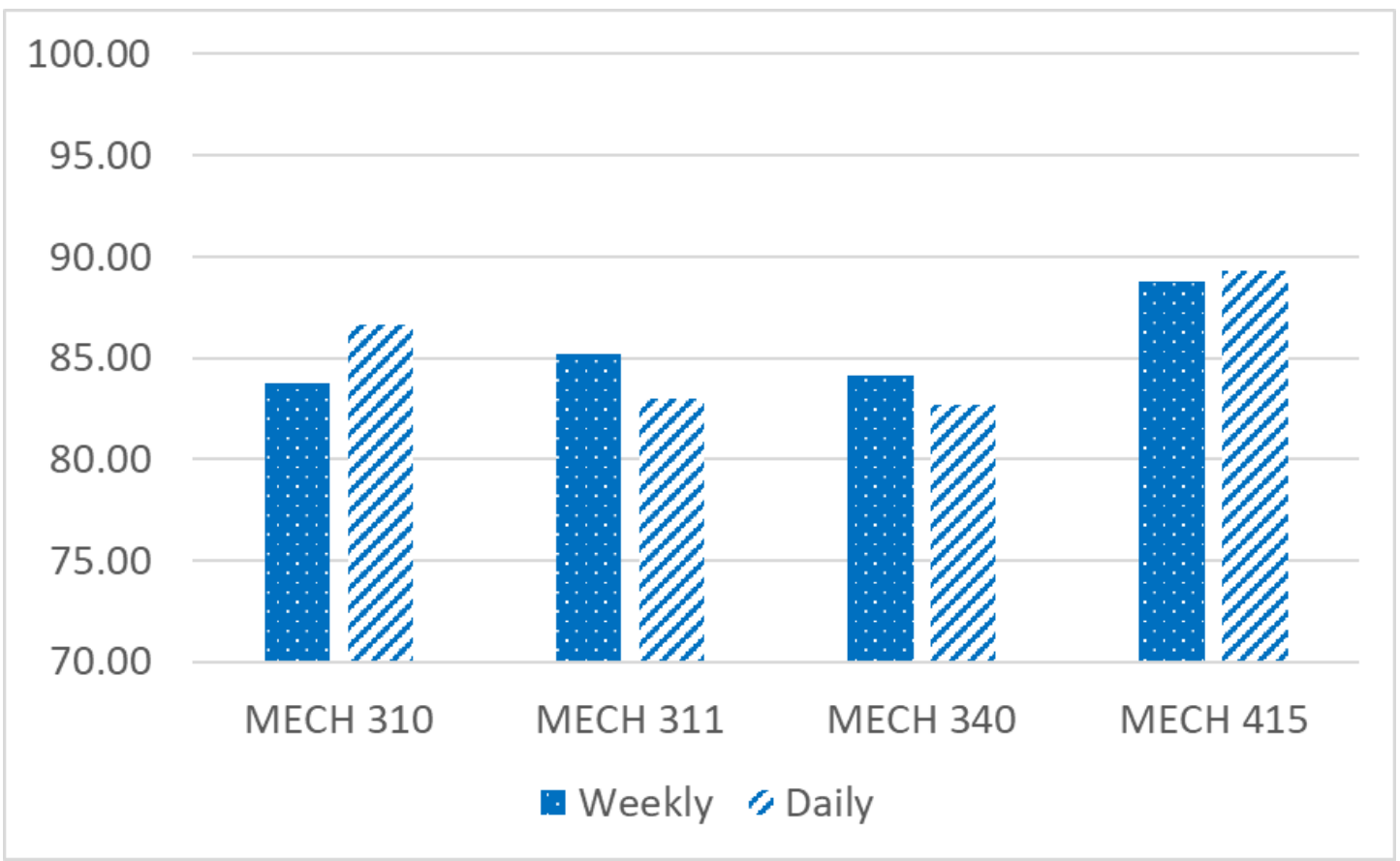

Figure 13. Average overall course grade - traditional students 


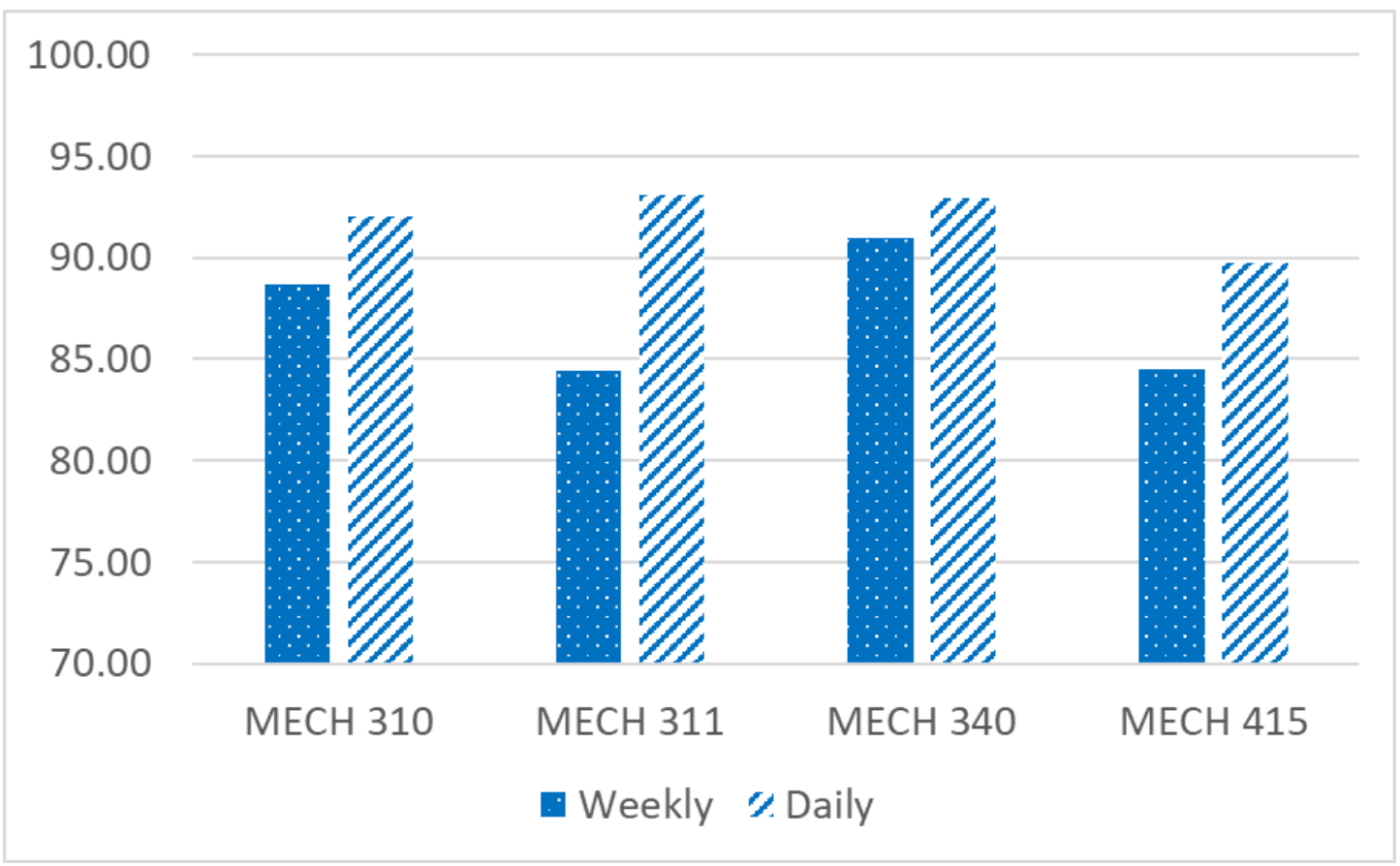

Figure 14. Average overall course grade - non-traditional students

The data in Figures 6, 7, and 13 display no discernible trend, moving up in two classes and down in two classes. Figures 8-12 show a modest improvement when switching from weekly to daily assignments, with three out of four courses showing an increase anywhere between 3 and $14 \%$. MECH 340 is the most common course to decrease instead of increase in this scenario. Figure 14 - average overall course grade of non-traditional students - is the only dataset to show the same trend in all four classes. Non-traditional students scored better overall in every class when switching to daily homework assignments.

In an attempt to adjust for variations in baseline performance, the GPA delta of each course was also measured. The average GPA of the student roster taking each course at the beginning of the semester was compared to the GPA of the course itself after final grades were determined. These results are shown below in Figure 15. 


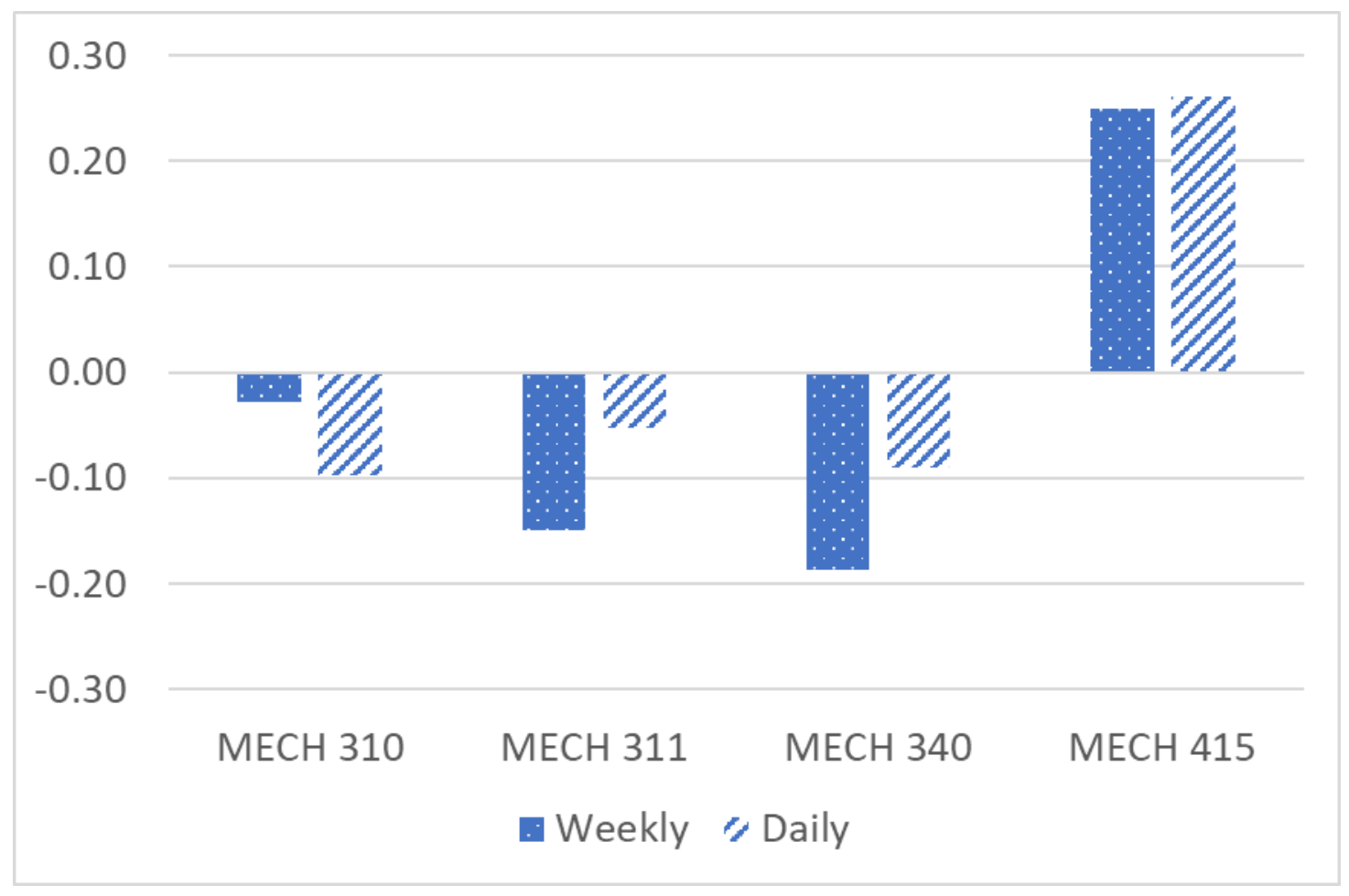

Figure 15. Average GPA Delta after conclusion of each course

Again, three out of four courses show a modest positive shift in student performance relative to their incoming GPA. Interestingly, the one course that shifted negatively in this measurement was not MECH 340 but MECH 310. The test grade data, overall course grade data, and GPA delta data all predict a slight improvement in performance with the adoption of daily homework submissions compared to weekly. However, the data for average homework grades does nothing to support this assertion, and the data collected for a total of 19 ABET embedded indicators spread across the four courses showed no evidence in favor of any grading strategy.

An anonymous survey was given to 58 students taking the senior level MECH 415 to gain further insight into student preference. These 58 students were a subset who were able to experience multiple homework strategies while being taught by the same instructor across MECH 310, MECH 311, and MECH 415. The students were asked to rank and comment on the three homework strategies examined in this paper. The five questions asked are displayed below in Table 1. 
Table 1. Survey questions asked to seniors about their homework preferences.

\begin{tabular}{|c|l|}
\hline 1 & Please rank your preference in homework processes $(1=$ best \& $3=$ worst $)$ \\
\hline 2 & My homework grade is better when I did homework (1 = highest grade \& 3 = worst grade $)$ \\
\hline 3 & My overall course grade is better when I did homework (1=highest grade \& 3=worst grade) \\
\hline 4 & I learned the most when I did homework (1 = most \& 3 = least) \\
\hline 5 & I spent the most time on homework when I submitted homework (1 = most \& 3 = least) \\
\hline
\end{tabular}

The 58 students surveyed selected the daily homework strategy as the most preferred in their answers to all five questions. The strongest preference occurred with questions 3 and 4, with $52 \%$ of students stating that their overall course grade was better and $62 \%$ of students stating that they learned the most with the daily homework assignments.

Interestingly, the students were the most evenly split on question 5, which asked about time spent on homework. One instructor collected time survey data by asking students daily to write down how much time they had spent out of class between the previous lecture and current one. These surveys indicate that time spent out of class between each lecture increased almost 50\% 22 minutes to 30 minutes - when homework was assigned daily. The time spent between each class also maintained a more level pattern, while time spent on weekly assignments tended to hover close to 0 and then spike the day before the assignment was due. Figures 16 and 17 display representative time survey data from MECH 340.

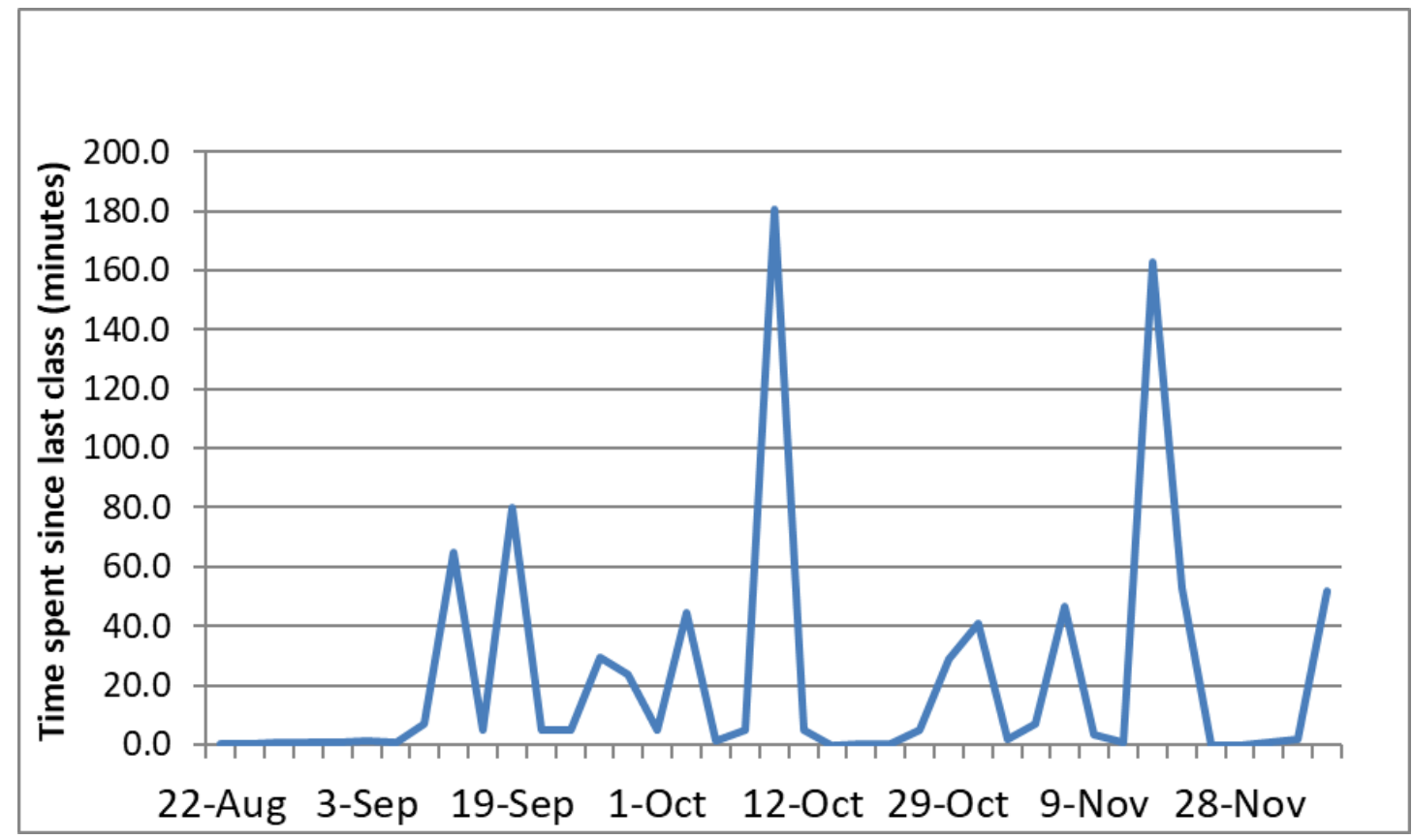

Figure 16. Time survey data from MECH 340, Fall 2018 (Weekly HW assignments) 


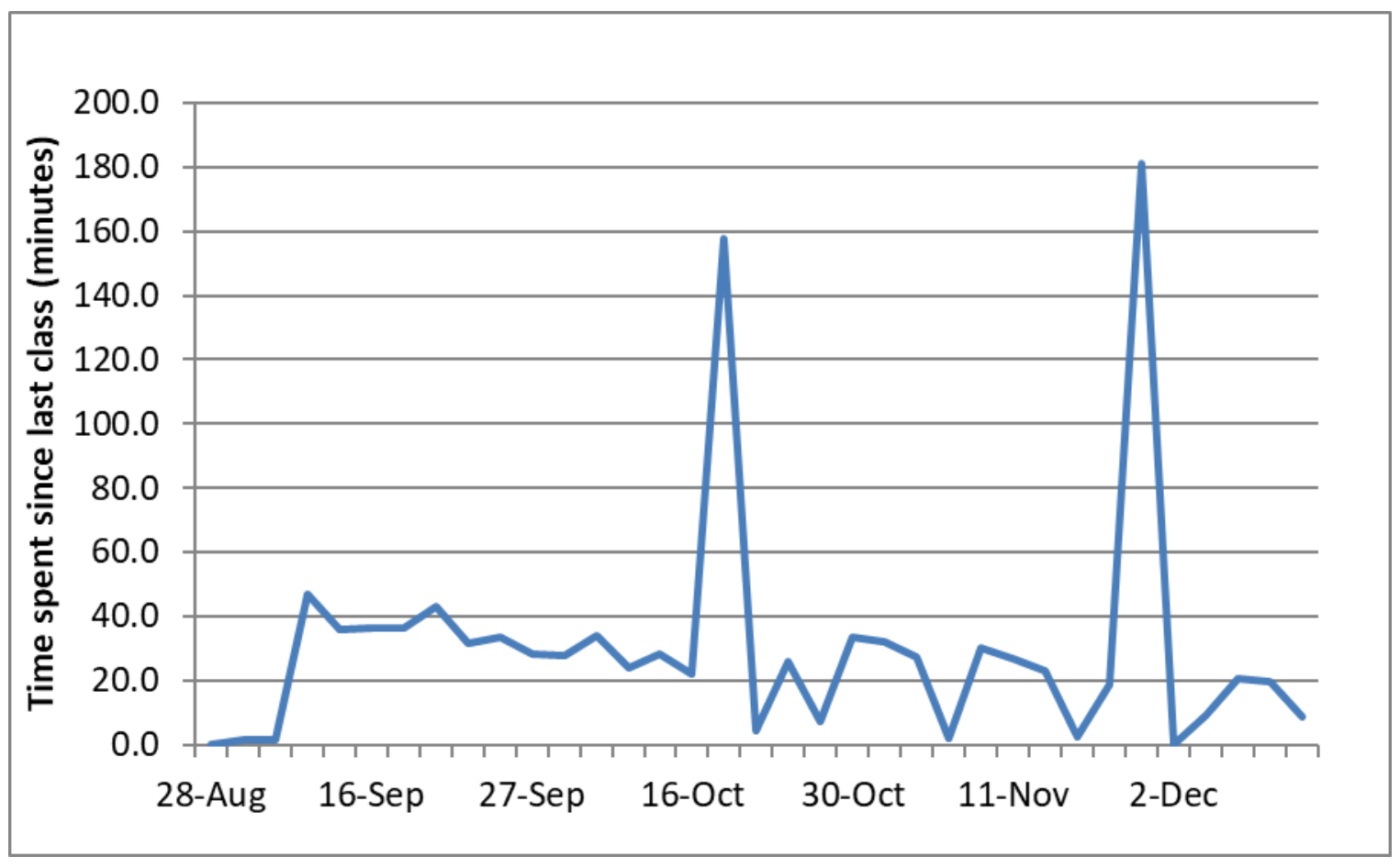

Figure 17. Time survey data from MECH 340, Fall 2019 (Daily homework assignments)

The drastic spikes in each time survey graph represent the day before an exam. These spikes are clearly present in both graphs, indicating that homework frequency certainly has no effect on the tendency of students to spend a considerable amount of time studying immediately before an exam.

Separate analysis of the 93 non-traditional students leads to similar results as the overall data. There were two notable exceptions to this similarity, however. First, data on these students indicate that the probability of assignments submitted on time remained level regardless of assignment frequency. The most obvious example of this occurred in MECH 340, where homework submission percentage among non-traditional students was $100 \%$ across multiple sections and semesters with a mixture of weekly and daily submissions. Second, the nontraditional students performed uniformly better in their overall course average with daily homework (as shown in Figure 14). In a similar vein, the non-traditional students in every section measured performed equal or better to their traditional counterparts on all four datasets presented in Figures 5-14 (Homework submission percentage, homework average, test average, and overall course average) $87 \%$ of the time.

These non-traditional students are older than the traditional students, and many have several years of military or work experience prior to their collegiate careers. The time management and organizational skills learned during this time appear to make these non-traditional students less susceptible to variations in performance that may be primarily caused by poor study habits and other similar factors in traditional students. As such, the consistent time spent doing daily assignments may benefit the non-traditional students more consistently, as seen when comparing Figures 13 and 14. 


\section{Conclusion}

Homework assignment frequency was tested across four courses. The results from this study suggest that the objective gains from using daily homework assignments are modest. Nontraditional students appear to already possess the soft skills that such a strategy encourages, and these students do appear to outperform their traditional counterparts and receive slightly more consistent benefits as a result. A higher frequency of homework assignments does greatly reduce late submissions, but a good percentage of these would-be late submissions appear to simply never get turned in. However, students displayed more consistent time spent on daily homework assignments, which indicates a more concrete time-management routine may be an effect of more frequent assignments. Furthermore, the students themselves are of the opinion that they learn the most from daily homework assignments. In the absence of any negative data, this argument alone may be good reason to switch to more frequent homework assignments as a measure to boost student confidence. 
1. Burnett, P. C., Fanshawe, J. P., Measuring school-related stressors in adolescents. Journal of Youth and Adolescence, Vol. 26, 1997.

2. Warton, P. M., The forgotten voices in homework: views of students. Educational Psychologist, Vol. 36, 2001.

3. Cooper, H., The battle over homework (2nd ed.). Corwin Press, 2001.

4. Landis, R. B., Studying Engineering: A Road Map to a Rewarding Career. Discovery Press, 2013.

5. Wood, T.W., Batouli, M., Michalaka, D., Brown, K., Book, E. K., Perspectives on an Innovative Homework Policy. American Society of Engineering Education SE Conference, 2019.

6. Taylor, J., An Analysis of the Relationships Between Homework Frequency and Homework Grading Procedures of Algebra 1 Teachers on Student Outcomes as Measured on the Algebra 1 End-of-course Examination. Dissertation, University of Central Florida, 2019.

7. Ellis, J., Hanson, K., Nuñez, G. et al., Beyond Plug and Chug: an Analysis of Calculus I Homework. International Journal of Research in Undergraduate Mathematics, Vol. 1, 2015.

8. Galyon, C. E., Voils, K. L., Blondin, C. A., Williams, R. L., The Effect of Randomized Homework Contingencies on College Students' Daily Homework and Unit Exam Performance. Innovative Higher Education, Vol. 40, 2015.

9. Book, E. K., Wood, T. A., Plumblee, J. M., Student and Faculty Perspective and Survey Results on an Innovative Homework Process. $126^{\text {th }}$ Annual American Society of Engineering Education Conference and Exposition, 2019.

10. Trautwein, U., The homework-achievement relation reconsidered: Differentiating homework time, homework frequency, and homework effort. Learning and Instruction, Vol. 17, 2007.

11. Dettmers, S., Trautwein, U., Lüdtke, O., The relationship between homework time and achievement is not universal : Evidence from multilevel analyses in 40 countries. School Effectiveness and School Improvement, Vol. 20, 2009.

12. Bronikowski S., Lowrance, C., and Viall, K., Lather, Rinse, Repeat: The Effect of Replacing Homework with Periodic Quizzes in Engineering Courses. American Society of Engineering Education Middle Atlantic Section Conference, 2011.

13. Allen, J. H., Fulcher J., Selvaraj, S. I., Assessment of Student Learning in Undergraduate Engineering Courses Using Quizzes In Lieu of Homework. $124^{\text {th }}$ Annual American Society of Engineering Education Conference and Exposition, 2017.

14. Li, W., Bennett, R., Olsen, T., McCord, R. Engage Engineering Students In Homework: Attribution Of Low Completion And Suggestions For Interventions. American Journal of Engineering Education, Vol. 9, 2018. 